Self-efficacy and its application in the treatment of knee osteoarthritis: a critical review

\section{Ray Marks}

School of Health and Behavioral Sciences, The City University of New York, York College, and The Department of Health and Behavior Studies, Columbia University, Teachers College, New York, USA

\section{Abstract}

Symptomatic knee osteoarthritis, a prevalent progressively disabling disease affecting one or both knee joints requires extensive selfmanagement. Self-efficacy, a psychological attribute generally denoting one's perceived belief about their ability to successfully perform a particular behavior, including health behaviors, is a significant predictor of psychological well-being, adherence to prescribed treatments, and pain coping mechanisms in persons with various forms of chronic disease, including arthritis. This paper examines the available peer-reviewed research published over the last 35 years detailing: i) the concept of self-efficacy, ii) the relationship between self-efficacy and adjustment to arthritis, iii) the research concerning self-efficacy in the context of knee osteoarthritis disability, and iv) some promising approaches for promoting the wellbeing of adults with knee osteoarthritis through the application of self-efficacy theory and other approaches. Based on this data, directions for future research and practice are offered.

\section{Introduction}

The arthritic diseases constituting a broad array of painful musculoskeletal and/or systemic conditions that can affect one or more joints, as well as the blood vascular and neurological systems, are commonly associated with symptoms of unrelenting pain, fatigue, anxiety, depression, as well as progressive functional, occupational and social limitations. As a result, these disorders are extremely debilitating and in the absence of a cure for any form of arthritis, adults with one or more of these conditions are often advised to carry out one or more self-management strategies in order to minimize their disability and maximize their independence and life quality. ${ }^{1}$

However, are individuals with disabling arthritis always able to confidently meet their day-to-day demands, plus the manifold task demands imposed on them by having to actively participate in their own management processes? Moreover, do they suffer from diminished self-confidence in one or more areas and are those with more confidence likely to have better health outcomes than those with less confidence, regardless of disease status, as shown in the literature for a variety of chronic diseases? Indeed, if the strength of one's personal confidence or self-efficacy beliefs, which are amenable to enhancement, are consistently impaired and can predict how much effort people will expend on tasks, and how persistent they will be in the face of challenges, obstacles, and aversive experiences, ${ }^{24}$ will more emphasis on assessing and fostering self-efficacy result in better health outcomes for individuals with arthritis in general, and for individuals with knee osteoarthritis, in particular? Given that self-efficacy is a well-studied psychological factor in the context of intervening upon a variety of chronic health-related challenges, including arthritis, but that most clinical studies on arthritis and self-efficacy focus on inflammatory or mixed forms of arthritis, where the types of pain or pathology among other factors might differ considerably, this paper set out to explore the literature detailing the association between the construct of self-efficacy and the symptoms of osteoarthritis in general, and knee joint osteoarthritis, in particular. This particular focus was taken firstly, because osteoarthritis is the most prevalent form of arthritis, and painful disabling knee osteoarthritis, the most common form of this condition, affects many older adults, where it is anticipated the role of self-efficacy perceptions in the context of maximizing coping efforts will potentially be magnified in light of the dual challenges posed by the disease, as well as the aging process. Second, in the specific case of knee osteoarthritis, where unrelenting pain, limited aerobic capacity, muscle weakness, joint instability, joint stiffness and swelling, along with a variety of comorbid health conditions, obesity, gait and sleep disturbances, plus work-related limitations and poor cognitive functioning may all co-exist, ${ }^{5}$ the ability to self-manage the disease, especially through exercise, as is commonly advocated, ${ }^{6}$ may prove extremely problematic. Third, since self-efficacy is amenable to quantification and can be boosted accordingly, it seemed reasonable to anticipate that an in-depth exploration of this construct could be especially valuable in the context of improving our understanding of the psychological features of knee osteoarthritis on health outcomes and in refining current clinical efforts to maximize the outcomes for this common chronically disabling and commonly incurable irreversible health condition, especially for those that may not be eligible or receive a total
Correspondence: Ray Marks, Columbia University, Teachers College, Department of Health and Behavior Studies, Box 114, 525 West 120th Street, New York, NY 10027, USA.

Tel. +1.212.678.3445 - Fax: +1.212.678-8259

E-mail: rm226@columbia.edu

Key words: arthritis, disability, knee osteoarthritis, osteoarthritis, pain, rehabilitation, self-efficacy, self-management.

Conflict of interests: the author reports no conflict of interests.

Received for publication: 31 July 2011.

Revision received: 13 July 2012.

Accepted for publication: 23 July 2012.

This work is licensed under a Creative Commons Attribution NonCommercial 3.0 License (CC BYNC 3.0).

(C) Copyright R. Marks, 2012

Licensee PAGEPress, Italy

Rheumatology Reports 2012; 4:e10

doi:10.4081/rr.2012.e10

knee joint replacement to relieve their pain.

However, even though a reasonably large body of related research makes it apparent that painful disabling knee osteoarthritis is likely to reduce the individual's sense of personal efficacy, as a whole, ${ }^{5-7}$ as well as their ability to meet specific challenges, quite markedly, ${ }^{7}$ the application of this knowledge for promoting a clear understanding of all factors that influence the well-being of knee osteoarthritis sufferer's remains relatively limited in this author's view. Indeed, knee osteoarthritis, which has specific causative and risk factors appears to be conceptually underestimated as an important public health issue as it is often accepted that this age associated disorder is inevitable. Moreover, while there is emerging research on this topic, there are variations in how often mental health issues, which can often accompany this disease, are measured clinically, and in the related research data bases, little emphasis has been placed on the importance of understanding the overlapping impact of mental and physical health in this condition. Furthermore, there seems to be no distinctive or unified body of research that can help clinicians better understand the strengths and weaknesses of the pertinent research and how to apply this research to intervene optimally in the context of chronically painful knee osteoarthritis, which according to World Health Organization data reported by Petrella et al. ${ }^{8}$ is poised to become among the top four causes of disability in women and to be among the top eight causes in men. To bridge this gap, this descriptive paper briefly reviews: i) the concept of self-efficacy, both general and 
domain-specific, plus the research linkage between self-efficacy and arthritis-related symptomology; ii) studies examining self-efficacy in the context of knee osteoarthritis, including the nature of the studies, the methods used to assess self-efficacy, possible shortcoming of the studies, and what these findings denote; and iii) some possible self-efficacy enhancing strategies that might be used in efforts to maximize outcomes in the clinical management of knee osteoarthritis. The paper concludes with some directives for practice as well as future research.

\section{Materials and Methods}

To obtain the desired data, research embedded in an array of peer-reviewed publications located in the Cinahl, Ovid Medline, Proquest, PsycINFO, PubMed and Social Science Citation databases over the years 1980-June 4, 2011 were examined. That is, relevant peerreviewed scientific papers published in the English language that fell under the key search terms: arthritis, knee, intervention, knee osteoarthritis, osteoarthritis, rehabilitation, and self-efficacy were identified and retrieved. The goal was to use these studies and their findings to highlight the importance of routinely examining self-efficacy in the clinical or surgical setting using appropriate tools and in devising appropriately tailored interventions to advance the scope of effective rehabilitation strategies for adults with knee osteoarthritis in line with current recommendations by Bierma-Zeinstra and Verhagen. ${ }^{9}$ To supplement this published information, some of this researcher's own findings as related to selfefficacy perceptions in the context of knee osteoarthritis are included. To limit the boundaries of this exploration, articles were only included if they adequately represented one of the three overarching themes of this paper and were rejected if they did not fall into one of these themes. All articles were read several times and the desired data were extracted and systematically tabulated to examine trends, and variations in the literature. All forms of self-efficacy were included, such as self-efficacy for pain control, and self-efficacy for managing other arthritis symptoms. No specific focused or meta-analysis could be conducted however, due to the highly varied data base, and variety of terms used in the literature to describe pain and other self-efficacy attributes such as pain self-efficacy, self-efficacy for pain beliefs, self-efficacy expectations and self-efficacy for pain control. Moreover, some studies focused on non-surgical patients, others on surgical patients, and the instruments used to measure self-efficacy were generally inconsistent across studies. As a consequence of the lack of depth in any one area of this topic in the prevailing literature, all related papers and levels of research as categorized by 0xford Best Practices Criteria (I-V) were deemed acceptable, although an attempt was made to only examine prospective studies to determine which methods are potentially useful for boosting self-efficacy in this population.

\section{Results}

The Ovid Medline (1948-2011) data base lists 13,282 articles that can be identified by the key word self-efficacy. It lists 290 articles that focus on self-efficacy and arthritis; 137 on self-efficacy and osteoarthritis; and 37 in selfefficacy and knee osteoarthritis. The key search results for PubMed (1980-2011, English language) revealed 599 papers on the general topic of arthritis and self-efficacy, 235 on osteoarthritis and self-efficacy, with the majority of 200 papers being published since 2000 , 15,012 papers on the topic of knee osteoarthritis, of which 137 included the term self-efficacy and where 117 of these were published since 2000 , with 21 using the term self-efficacy in the context of intervention outcomes. Cinahl, 1985-June 4, 2011 had 8189 articles using self-efficacy as a key word; 209 for selfefficacy and arthritis; 105 for osteoarthritis and self-efficacy; 60 for self-efficacy and knee osteoarthritis. PsycINFO had 14 articles on self-efficacy and knee osteoarthritis, but no unique information. After downloading and examining pertinent data that met the review criteria, from the 24,540 PubMed items and 8189 Cinahl articles that contained the term self-efficacy, these data were categorized into four predominant themes as follows.

\section{Self-efficacy theory: back- ground and concept}

In the 1970's Albert Bandura, ${ }^{2}$ a well-known researcher and psychologist, began to examine the concept of self-efficacy, which refers to one's personal belief in his or her ability to successfully organize and implement a specific task, under different contextual situations. Based on this research, Bandura observed selfefficacy perceptions, which can be strengthened, potentially explained the discrepancy between people having knowledge about a skill and the actual performance of this skill. Over the years, Bandura's research has shown important links between multiple behaviors and self-efficacy perceptions and that the strength of one's self-efficacy beliefs can influence their motivation levels, thought patterns, moods, emotional reactions and attitudes. Moreover, self-efficacy perceptions can mediate the capacity and willingness to elicit behaviors that influence health and promote wellbeing, despite disconfirming experiences. This research further supports the view that self-efficacy judgments can determine the extent to which a person will be disabled as well as whether they will perform the adaptations needed to deal with one or more chronic illnesses and their treatments.

In addition, this work points to how much effort will be expended on a task - and for how long - in the face of obstacles and aversive experiences..$^{2,3}$ Accordingly, since 1977, it has been increasingly evident that self-efficacy beliefs are powerful predictors and/or mediators of a variety of health-related behaviors and practices. Indeed, because self-efficacy beliefs can predict the amount of effort and perseverance expended in reaching a goal, plus the development and selection of goals and goaldirected behaviors, they have become of immense importance in the context of influencing health outcomes among people with chronic illnesses. In addition, to measure overall confidence and beliefs, it has been possible to develop instruments to estimate the nature of the individuals' self-perceptions to manage their challenges across different health situations with a fair degree of accuracy. This set of behavior specific beliefs, is generally distinct from the perceived general self-efficacy or global confidence an individual may exhibit, in the context of life in general, and may be a neglected area of relevance to arthritis care and research efforts. However, this paper will report on the available literature on this topic, which focuses almost exclusively on domainspecific self-efficacy attributes.

\section{Self-efficacy and arthritis: general observations}

Although psychological assessments and treatments are less common than physical approaches used to treat arthritic conditions, as detailed in the results of the present article search, the prevailing literature houses a fairly large volume of studies published over the last two decades that show a significant relationship exists between pain and disability as experienced by adults with inflammatory arthritis or a combination of one or more arthritic conditions, and the construct of selfefficacy. In this context, arthritis self-efficacy, a term commonly used to describe the magnitude of the ability to self-manage the disease as denoted by three self-efficacy domain subscales related to pain, function and other disease symptoms has specifically been shown to predict the rheumatoid arthritis patients' 
health status and adherence to health recommendations, ${ }^{10,11}$ plus the prevailing degree of depression, ${ }^{12}$ fatigue,,$^{13}$ daily pain ratings, coping efficacy, ${ }^{14}$ coping capacity, ${ }^{15}$ analgesic usage, ${ }^{16}$ pain behaviors and health outcomes. ${ }^{17-19}$ Another related body of research shows physical activity participation, often crucial for promoting wellbeing among arthritis patients can be influenced significantly by the prevailing level of self-efficacy for the desired activity. ${ }^{20}$ Importantly, self-efficacy is also found to influence resilience, ${ }^{21}$ the extent of psychological distress and emotional wellbeing, functional ability, and fatigue states. ${ }^{22,23}$ Moreover, correlational analyses have shown significant associations between changes in self-efficacy (particularly total self-efficacy) and changes in selected measures of depression, pain, health status, and disease activity of cases with rheumatoid arthritis, ${ }^{24}$ as well as medication adherence, which may have a profound bearing on arthritic disease status, ${ }^{25,26}$ and its immense health costs. ${ }^{26}$

\section{Self-efficacy and osteoarthri- tis: findings from studies on knee osteoarthritis}

Overview of research issues and findings

As with the studies discussed above for arthritis in general, the related self-efficacy literature can be categorized in terms of its relationship to pain, disability, and cognitive attributes, and its role in both conservative as well as surgical treatment approaches in the context of osteoarthritis in general, and to a lesser degree in the context of knee osteoarthritis, the most common form of the disease. However, although considerable progress has been made since 2000 to conduct more specific research on osteoarthritis and self-efficacy, specific knowledge remains limited as data are frequently presented as an admixture of summary data from cases of inflammatory arthritis, and/or osteoporosis cases. As well, several studies focusing on osteoarthritis and self-efficacy have examined various forms of this condition simultaneously, so the individual associations relevant specifically to knee osteoarthritis are hard to discern. Indeed, although knee osteoarthritis is the most prevalent form of this condition, only slightly more than fifty percent of the available reports in the self-efficacy and osteoarthritis literature focus solely on samples of knee osteoarthritis and aspects of self-efficacy in relation to this condition.

Unfortunately, in addition to the compara-

Table 1. Selected studies demonstrating significant relationships between self-efficacy levels, several behavioral factors, and disease outcomes among samples of adults with knee osteoarthritis using different approaches.

\begin{tabular}{|c|c|c|c|c|c|}
\hline Domain & Authors & $\begin{array}{l}\text { Level research } \\
\text { evidence (I-V)* }\end{array}$ & $\begin{array}{l}\text { Sample } \\
\text { size }\end{array}$ & SE measure** & Finding \\
\hline \multirow[t]{5}{*}{ Function } & Baker et al..$^{27}$ & I & 46 & $\begin{array}{l}\text { Ewart's scale for: } \\
\text { lifting, stairs, jogging, } \\
\text { walking, pushups }\end{array}$ & Gait SE correlated with knee strength \\
\hline & Focht et al.28 & II & 316 & $\begin{array}{l}\text { Walking SE }(0-100) \\
\text { Stairclimb SE }(0-100)\end{array}$ & SE mediated function \\
\hline & Maly et al. ${ }^{29}$ & IV & 54 & ASE function subscale & $\begin{array}{l}\text { Task SE explained a high degree of functional } \\
\text { ability and was related to stiffness, strength, and } \\
\text { depression }\end{array}$ \\
\hline & Rejeski et al. ${ }^{30}$ & IV & 79 & Task-specific SE & $\begin{array}{l}\text { SE predicted stair climbing, lifting/carrying ability; } \\
\text { influenced ability/difficulty perceptions, } \\
\text { movement rate. } \\
\text { SE and performance relationships were similar } \\
\text { to physiological measures }\end{array}$ \\
\hline & Sharma et al..$^{31}$ & II & 285 & ASE function scale & SE is protective against poor outcomes \\
\hline Pain & Creamer et al. ${ }^{32}$ & IV & 69 & ASE pain scale & Inverse correlations exist between disability and pain SE \\
\hline \multirow[t]{8}{*}{ Pain + Function } & Bennet et al. .33 & IV & 39 & ASE subscales & $\begin{array}{l}\text { Those with lower function SE may respond better } \\
\text { to glucosamine than those with high SE }\end{array}$ \\
\hline & Harrison $^{34}$ & IV & 50 & ASE subscales & $\begin{array}{l}\text { Functional SE + balance account for } 74 \% \text { variance } \\
\text { in function. } \\
\text { Pain SE correlates with pain, functional difficulty and SE }\end{array}$ \\
\hline & Keefe et al. .35 & IV & 130 & 20-item ASES & Adaptive pain coping correlates with SE \\
\hline & Khan et al..$^{36}$ & IV & 134 & $\begin{array}{l}\text { SE managing } \\
\text { recovery } 5 \text {-item } \\
\text { modified ASES }\end{array}$ & $\begin{array}{l}\text { Emotional support increases SE for recovery, } \\
\text { problem support weakens SE belief }\end{array}$ \\
\hline & McKnight et al. ${ }^{37}$ & II & 254 & ASE combined scales & $\begin{array}{l}\text { Catastrophizing predicted SE; SE mediated between } \\
\text { catastrophizing/physical function }\end{array}$ \\
\hline & Morone et al. ${ }^{38}$ & IV & 88 & Chronic Pain SE Scale & Gait speed is related to SE $-78.18 \pm 13.8$ on $(0-100)$ scale \\
\hline & Pells et al. ${ }^{39}$ & IV & 174 & ASE pain subscale & $\begin{array}{l}\text { Pain SE accounted for } 14 \% \text { of variance in pain; Function } \\
\text { SE accounted for } 10 \% \text { variance in disability; } \\
\text { SE for eating control accounted for } 28 \% \text { variance } \\
\text { in eating behaviors }\end{array}$ \\
\hline & Wright et al..$^{40}$ & IV & 275 & 20-item ASES & $\begin{array}{l}\text { Higher SE is linked to lower pain and better function } \\
\text { through resilience }\end{array}$ \\
\hline
\end{tabular}

ASE/S, arthritis self-efficacy Scale; SE, self-efficacy. *Levels of Research Evidence as adopted by American Academy of Orthopaedic Surgeons, September 2004: I=high quality randomized controlled trial/systematic review; II=prospective study;systematic reviews with inconsistent results; III=case control; retrospective study; review of level II studies; IV=case series; V=expert opinion. **Participants indicate their certainty to perform particular tasks (relating to pain management and 9 relating to function) on a 10 point scale, ranging from very uncertain (score of 1 ) to very certain (score of 10 ). For each subscale, the mean of the respective items was taken as the total score. 
tively small number of specific reports on this topic in the available literature, in light of the prevalence of this condition, a cursory overview of the available research reveals a wide array, rather than any consistent research approach that focuses on understanding a specific self-efficacy domain that can be readily synthesized and analyzed for trends. Moreover, within the more common domains studied, many have been studied in the context of cross-sectional or observational studies, several differing types of self-efficacy have been examined, and no consistently applied terminology or uniform measurement approach can be observed among these published works (Table 1). However, as outlined in the available literature and in Table $1,{ }^{27-40}$ as in studies conducted on cases with inflammatory arthritis, the relationship between the chief categories of pain, function, and other symp- tom management self-efficacy and the extent of the pain and function experienced among adults with knee osteoarthritis, ${ }^{26}$ seems to be a consistently significant one, regardless of the attribute measured, the research design, terminology used or the sample size and its characteristics. In another application, Keefe et $a l .{ }^{35}$ who studied 40 men and women with knee osteoarthritis, found participants with higher pain self-efficacy scores responded more favorably to artificial pain stimuli than those with lower pain self-efficacy scores, suggesting that efforts to enhance pain self-efficacy may improve a patient's subjective perception of their condition. Moreover, improving the ability to self-manage pain may improve the functional ability of adults with knee, ${ }^{26}$ as well as the extent of activity participation. ${ }^{35}$ Other related research shown in Table 1 confirms that a significant relationship between the magnitude of the self-efficacy beliefs held by adults with knee osteoarthritis and their pain and mobility scores, ${ }^{38}$ and can explain up to $21 \%$ of the variance in the performance ability of adults with painful disabling knee osteoarthritis, especially those challenged by muscular weakness of the lower extremities. ${ }^{30-41}$

In addition, another domain of self-efficacy termed coping self-efficacy is found to mediate between excessive pain catastrophizing and its effect on physical functioning among individuals with early knee osteoarthritis, ${ }^{37}$ suggesting an additional avenue for intervening early on in the disease process to allay dysfunction. As outlined in Figure 1, there may also be reciprocal influences between self-efficacy perceptions and life satisfaction, ${ }^{42}$ sleep rates, often disturbed in older adults with knee osteoarthritis, ${ }^{43}$ and the ability to maintain a healthy weight and pursue healthy eating

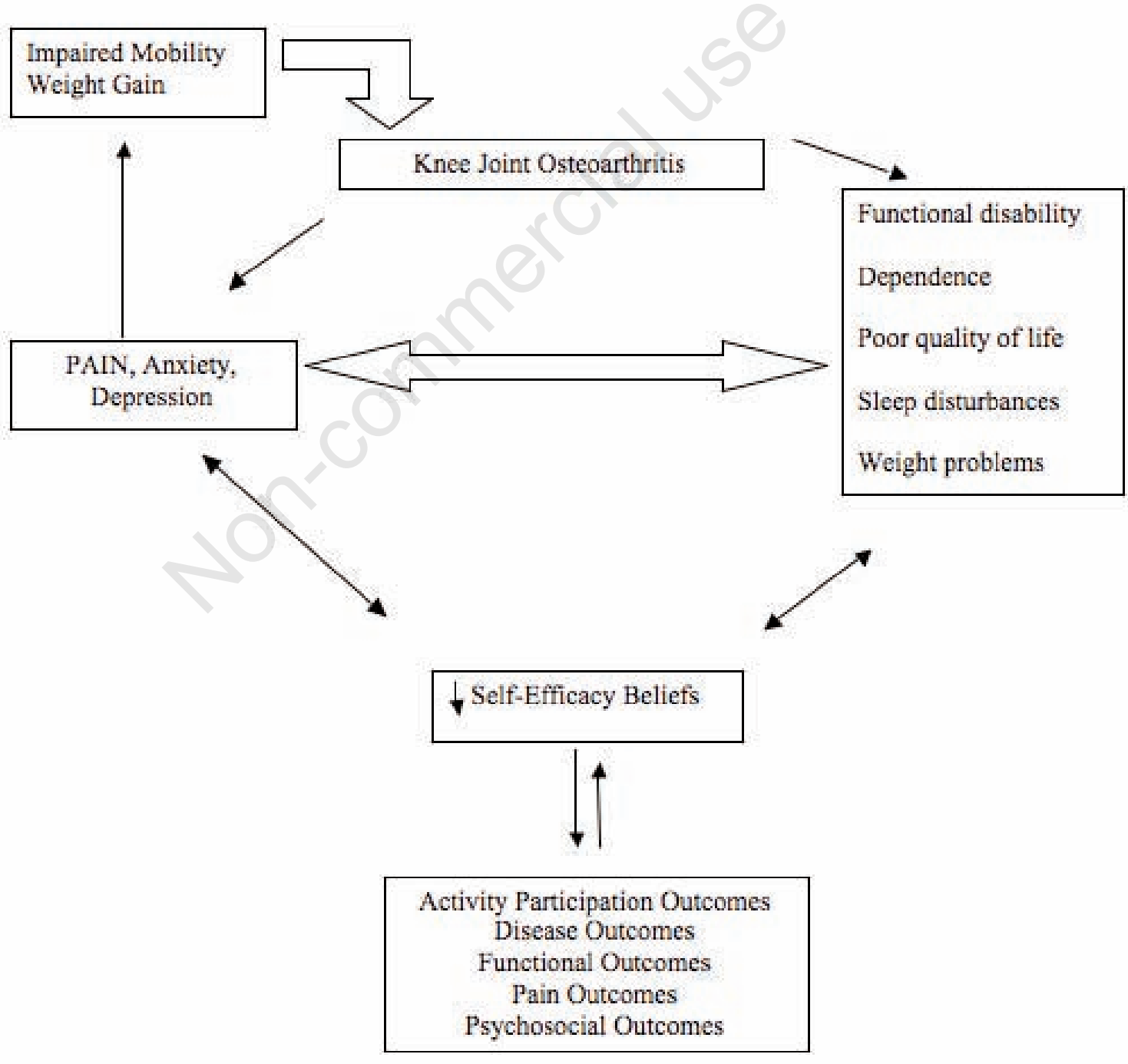

Figure 1. Hypothetical model of interrelationships between knee osteoarthritis and self-efficacy beliefs. 
behaviours $(\mathrm{P}<0.0001)$, especially in the overweight or obese adult with knee osteoarthritis, ${ }^{39}$ that could influence disease progression and outcomes. This is supported by a fairly substantive body of research reporting higher level, rather than lower level self-efficacy beliefs are positively correlated with better functional outcomes among adults with knee osteoarthritis as detailed in Table 1.44-49

Moreover, in addition to the global impact of the disease per se, several disease-associated factors are found to reduce the individual's self-efficacy for one or more important day to day behaviours, including declines in knee strength capacity and pain coping ability.

As a result, a compelling number of studies reveal that individual's with knee osteoarthritis and poor self-efficacy for one or more desirable self-management practices, may have less ability to adjust to their condition, ${ }^{40}$ lower motivation for exercise, often seen as a potentially essential intervention component for people with knee osteoarthritis ${ }^{50}$ plus heightened pain and functional disability, ${ }^{28,32,40}$ and depression levels, which can serve as a mediator of exercise and dietary efforts, ${ }^{51}$ than more confident cases.

Consequently, efforts to assess clinical correlates known to impact self-efficacy, as well as efforts to directly assess, monitor and strengthen a client's self-efficacy are likely to enhance the health outcomes of any particular individual with this condition. ${ }^{30}$ However, since self-efficacy perceptions are commonly behaviour specific, and adults with this condition often need to undertake multiple tasks, it seems likely that successful efforts in this regard will be contingent on understanding where self-efficacy perceptions are especially suboptimal. As well, in light of the considerable clinical diversity that can prevail among cases diagnosed as having knee osteoarthritis, a very careful analysis of the individual's personal perceptions about their condition and their ability to manage this is desirable given some individuals may clearly be more confident than others and individuals themselves may be quite confident in one behavioural domain, and not another. For example, an individual confident about undertaking walking and stairclimbing in efforts to enhance function, ${ }^{28}$ may not have the confidence needed to resist eating in efforts to control their weight, ${ }^{39,52}$ the confidence for assistive device usage, ${ }^{53}$ the confidence to self-manage pain and the confidence they can prevent excessive functional declines. ${ }^{34,54}$ Additionally, a careful initial discussion with the affected individual may provide a better understanding of the person's intra-individual beliefs including their outcome expectancies and/or motivation to comply with recommendations as well their views on barriers and appropriate and adequate incentives or resources needed to permit selfefficacy beliefs to translate into desired activities. ${ }^{30,34}$ Nonetheless, it seems apparent, that even if the strength of a patient's self-efficacy beliefs are not necessarily the same across samples or within the same samples when different behavioural attributes are considered, data in Table 2 indicate many individuals with a diagnosis of knee osteoarthritis are likely to

Table 2. Table depicting variations in the self-efficacy measurement approaches and their outcomes as identified by mean scores and their standard deviations recorded for different samples of adults with knee osteoarthritis in the context of correlational and comparative studies.

\begin{tabular}{|c|c|c|c|}
\hline Authors & Knee osteoarthritis sample & Self-efficacy instrument & Mean scores \\
\hline Allen et al.55 & $\begin{array}{l}221 \text { African Americans } \\
270 \text { Caucasians }\end{array}$ & 8-item ASE (1-10 point scale) & $\begin{array}{l}\text { 5.5 African-Americans } \\
\text { 6.0 Caucasians }\end{array}$ \\
\hline Bennett et al. ${ }^{33}$ & $\mathrm{~N}=39 ;$ av age $=53.6 \pm 13.1$ & ASES pain \pm function & $\begin{array}{l}\text { Pain }=5.84 \pm 1.84 \\
\text { Function }=8.17 \pm 1.69\end{array}$ \\
\hline Focht et al..$^{28}$ & $\mathrm{~N}=316 ; 4$ groups & $\begin{array}{l}\text { Stair climbing SE } \\
\text { Walking SE (10-100) }\end{array}$ & $\begin{array}{l}\text { Educ grp }=70.24 \pm 28.75 \\
\text { Educ grp }=67.88 \pm 31.95\end{array}$ \\
\hline King et $a l .56$ & $\mathrm{~N}=14 ;$ av. age $=48.35 \pm 6.51$ & 3 ASE scales $(0-10)$ & $\begin{array}{l}\text { Pain }=6.45 \pm 2.23 \\
\text { Function }=8.37 \pm 0.86 \\
\text { Other }=7.66 \pm 1.54\end{array}$ \\
\hline Keefe et al. .5 & $\mathrm{~N}=130$ & 3 ASE scales (10-100) & $\begin{array}{l}\text { Pain }=59.97 \pm 18.98 \\
\text { Function }=75.07 \pm 20.00 \\
\text { Other }=67.02 \pm 17.09\end{array}$ \\
\hline Lamb et al. ${ }^{58}$ & $\mathrm{~N}=121 ;$ av.age $=68 \pm 8.5$ & Pain \pm function SE & $\begin{array}{l}\text { Pain }=27 \pm 10.24 \\
\text { Function }=35.1 \pm 12.34\end{array}$ \\
\hline Morone et al. ${ }^{38}$ & $\mathrm{~N}=88 ;$ av. age $=71.5 \pm 5.4$ & Chronic pain SE scale (0-100) & $\mathrm{CPSE}=78.18 \pm 13.3$ \\
\hline Murphy et al..$^{59}$ & $\begin{array}{l}\mathrm{N}=54 \\
\mathrm{E}=26 ; \text { av. age }=74.8 \pm 7.3 \\
\mathrm{C}=28 ; \text { av. age }=75.8 \pm 7.1\end{array}$ & ASES combined scores (1-10) & $\begin{array}{l}\text { Pain } \pm \text { other } \\
\mathrm{E}=7.2 \pm 1.8 \\
\mathrm{C}=6.9 \pm 1\end{array}$ \\
\hline Rawiworrakul et al. ${ }^{60}$ & $\begin{array}{l}\mathrm{N}=53 \\
\mathrm{E}=25 ; \text { av. } \text { age }=58.8 \\
\mathrm{C}=28 ; \text { av. } \operatorname{ag} \mathrm{e}=60.6\end{array}$ & SE for exercise scale $(0-10)$ & $\begin{array}{l}\text { SEE } E=5.0 \pm 2.15 \\
C=5.77 \pm 1.91\end{array}$ \\
\hline Shen et al. ${ }^{61}$ & $\mathrm{~N}=48$, av. age $64.4 \pm 8.3 ; 88 \% \mathrm{~F}$ & Chronic pain SE Scale (0-100) & $\begin{array}{l}\text { Pain }=60.3 \pm 37.4 \\
\text { Function }=67.3 \pm 40.1 \\
\text { Other }=63.1 \pm 37.3\end{array}$ \\
\hline Shlenk et al..$^{2}$ & $\begin{array}{l}\mathrm{N}=26 ; \text { av. age }=53.2 \pm 9.8 ; 99 \% \mathrm{~F} \\
\mathrm{E}=13 \\
\mathrm{C}=13\end{array}$ & Exercise SE scale (0-100) & $\begin{array}{l}\mathrm{E}=57.8 \pm 22.2 \\
\mathrm{C}=60.3 \pm 32.7\end{array}$ \\
\hline Wu et al.63 & $\begin{array}{l}\mathrm{N}=259 \\
\mathrm{E}-114 \text { cases, av. age } 67.27 \pm 10.05 \\
\mathrm{C}=91 \text { cases, av. age } 68.18 \pm 11.21\end{array}$ & ASES - pain \pm other $(0-10)$ & $\begin{array}{l}\text { Pain }=33.02 \pm 11.27 \mathrm{E} \\
32.55 \pm 12.20 \mathrm{C} \\
\text { Other }=42.19 \pm 14.30 \\
\text { E } 44.74 \pm 12.30 \mathrm{C}\end{array}$ \\
\hline
\end{tabular}

Av, average; ASES, arthritis self-efficacy scale; C, control; Educ, educational; E, experimental; Grp, group; SE, self-efficacy. 
be less than fully confident about performing one or more of those behavioural tasks likely to influence their disability.

\section{Measurement considerations}

While the importance of self-efficacy in selfmanagement of knee osteoarthritis seems well-supported as outlined above, the utility of any measurement approach in this regard is likely to be dependent on, in part, the nature of the instrument used to assess self-efficacy, plus the method applied to summarize these results. For example, the use of a summary score to assess a patient's specific confidence profile may obscure precisely where an individual's confidence is limited and hence what is needed to specifically foster optimal outcomes, as suggested by results of McKnight $e t$ $a l .{ }^{37}$ That is, using cumulative scores to examine the magnitude of a client's behavioral-specific self-efficacy beliefs may fail to highlight just how challenged individuals' with this condition can become in certain spheres-despite their knowledge of the benefits that the tasks recommended will benefit them, as well as knowing how to carry out the task. Furthermore, since the three Arthritis SelfEfficacy Subscales most commonly used in the research on arthritis are not perfectly correlated as shown by Keefe et al. and King et al. those applying these measurement strategies should perhaps remain cognizant of this potential limitation when using these data to design programs. ${ }^{10,27,35}$ In addition to the above, more work to better examine and capture the vastly different domains of behavior that can impact knee osteoarthritis and the extent of this impairment is especially indicated in order to examine if intervention programs will benefit from focusing on multiple rather than single self-efficacy enhancing strategies. ${ }^{30}$

To support this statement, we recently reexamined data from a previously published study that showed distinct variations in perceived self-efficacy beliefs among communitydwelling cases with knee osteoarthritis older than 60 years of age with mild to moderate unilateral or bilateral knee joint osteoarthritis (Table 3), and where the individual and mean self-efficacy scores tend to vary relative to extent of disease, gender and nature of the arthritis self-efficacy scale domain. ${ }^{51-64}$ Also noteworthy was that the item to total correlations examined separately for each domain, were found to vary from $\mathrm{r}=0.664-0.797, \mathrm{P}<0.01$ for pain self-efficacy domain scores and from $\mathrm{r}=0.682-0.870, \mathrm{P}<0.01$ for the other symptoms self-efficacy domain scores. Moreover, not all items on the 5 -item pain self-efficacy subscale were significantly correlated with a traditional measure of pain intensity known as the visual analogue scale, suggesting they might be capturing separate elements of the subjective pain experience. As well, among the 11 arthritis self efficacy survey item responses (5 for pain and 6 for other symptoms management), compared between a representative sample of those women deemed healthy and those with a past history of cardiovascular disease, a very common problem in this population, those with a comorbid health condition had less overall confidence in these domains $(71.75 \pm 5.50$ vs $78.33 \pm 6.07$, respectively). Other data revealed cases with knee osteoarthritis may be more vulnerable to poor outcomes if they have depressive symptoms as measured by the Center for Epidemiologic Studies Depression Scale, which were more strongly related to their total self-efficacy scores than their actual pain experiences $(\mathrm{r}=-0.75, \mathrm{P}=0.001 ; \mathrm{r}=-0.28$, $\mathrm{P}=0.069$, respectively), as well as to their item scores (items 1, 2 and 3 on pain self-efficacy subscale and items 3,5 , and 6 on the other symptoms self-efficacy scale) (Table 4 ).

In summary, and in the context of applying the knowledge about the role of the relationship of self-efficacy to our understanding of the pathogenesis of knee osteoarthritis, as well as its treatment, research shows this construct has a consistent relationship with a

Table 3. Descriptives of $\mathbf{n}=\mathbf{2 8}$ cases knee osteoarthritis 60 years and older, drawn randomly from a larger study sample of 100 cases and highlighting variations in magnitude of the mean and range of 5 item scores for pain self-efficacy and 6 items of other symptoms selfefficacy subscale of the arthritis self-efficacy instrument (range 10-100) and trends based on disease classification.

\begin{tabular}{|c|c|c|c|c|}
\hline Variable & Mean \pm SD & Range & $95 \% \mathrm{CI}$ & P value \\
\hline Age year & $73.71 \pm 7.00$ & $61-89$ & $71.00-76.43$ & \\
\hline Body mass index & $28.4 \pm 3.70$ & $21-35$ & 26.9-29.8 & \\
\hline $\begin{array}{l}\text { \% Female } \\
\text { \% Unilateral cases }\end{array}$ & $\begin{array}{l}82 \\
65\end{array}$ & & & \\
\hline $\begin{array}{l}\text { Pain SE (10-100) } \\
\text { Items: How certain are you-you can } \\
\text { 1. Decrease your pain quite a bit } \\
\text { 2. Continue most of your daily activities } \\
\text { 3. Keep pain from interfering with sleep } \\
\text { 4. Reduce your pain in small way without medication } \\
\text { 5. Reduce your pain in a large way without medication }\end{array}$ & $\begin{array}{l}69.00 \pm 20.27 \\
62.86 \pm 30.90 \\
68.57 \pm 27.18 \\
69.29 \pm 28.79 \\
74.82 \pm 26.44 \\
73.39 \pm 26.39\end{array}$ & $\begin{array}{l}26-100 \\
10-100 \\
10-100 \\
10-100 \\
10-100 \\
10-100\end{array}$ & $\begin{array}{l}61.36-76.93 \\
50.88-74.84 * \\
58.03-79.11 \\
58.12-80.45 \\
64.57-85.07 \\
63.16-83.63\end{array}$ & \\
\hline Disease classification & & & & 0.360 \\
\hline $\begin{array}{l}\text { 1. Unilateral } \\
\text { 2. Bilateral }\end{array}$ & $\begin{array}{l}66.33 \pm 19.7 \\
73.80 \pm 21.34\end{array}$ & $\begin{array}{l}26-100 \\
40-100\end{array}$ & $\begin{array}{l}56.52-76.15 \\
59.39-89.01\end{array}$ & \\
\hline $\begin{array}{l}\text { Other SE (10-100) } \\
\text { Items: How certain are that you can: } \\
\text { 1. Control your fatigue } \\
\text { 2. Be active without aggravating your condition } \\
\text { 3. Help yourself feel better if blue } \\
\text { 4. Manage pain during daily activities } \\
\text { 5. Manage symptoms and do things you enjoy } \\
\text { 6. Deal with frustration of arthritis }\end{array}$ & $\begin{array}{l}75.71 \pm 25.738 \\
70.00 \pm 31.032 \\
76.43 \pm 28.312 \\
75.71 \pm 22.678 \\
72.14 \pm 28.068 \\
71.07 \pm 29.356\end{array}$ & $\begin{array}{l}40-100 \\
20-100 \\
10-100 \\
10-100 \\
40-100 \\
10-100 \\
10-100\end{array}$ & $\begin{array}{l}66.15-82.44 \\
66.73-85.69 \\
57.97-82.03 * \\
65.45-87.41 \\
66.92-84.51 \\
61.26-83.03 \\
59.69-82.45\end{array}$ & \\
\hline $\begin{array}{l}\text { Disease classification } \\
\text { 1. Unilateral } \\
\text { 2. Bilateral }\end{array}$ & $\begin{array}{l}70.68 \pm 21.7 \\
78.50 \pm 22.32 \\
\end{array}$ & $\begin{array}{l}43-100 \\
40-100\end{array}$ & $\begin{array}{l}59.85-81.52 \\
67.33-94.27\end{array}$ & 0.375 \\
\hline
\end{tabular}

$\mathrm{Cl}$, confidence interval; $\mathrm{SE}$, self efficacy; SD, standard deviation. *Items where low self-efficacy was most evident. 
variety of knee osteoarthritis symptoms, and signs of depression, poor coping skills, harmful eating behaviors, and physical performance deficits..$^{29,46}$ Engel et al. ${ }^{64}$ too, found self-efficacy beliefs predicted the extent of gains in physical and mental health in adults recovering from total knee replacement surgery, a common intervention for adults with end-stage knee osteoarthritis. Low self-efficacy may also explain poor outcomes of knee osteoarthritis cases with comorbid health problems such as cardiovascular disease and depression.

However, even though studies such as those outlined in Table 1 provide a rationale for examining and intervening upon the attribute of self-efficacy among adults with knee osteoarthritis, self-efficacy scores obtained from different samples show self-efficacy levels may not be uniformly affected, even when the same instrument approach is utilized (Table 2). Moreover, even though average selfefficacy scores as outlined in Table 2 depict that knee osteoarthritis cases are commonly less than fully confident in general about their ability to control pain and other salient disease associated behaviors, as indicated by large standard deviation scores, some individuals may be extremely unconfident, while others may be completely confident. That is, in addition to revealing less than optimal confidence on similar domains, and different levels of confidence on different domains, different subgroups of individuals with this condition can display varying rather than uniform patterns of behavioral self-confidence that should be examined and considered in the selection and delivery of long-term health recommendations.

In light of the powerful connection consistently observed between knee osteoarthritis outcomes and self-efficacy levels, it appears more research and discussion directed towards adopting a universally validated and agreed upon standardized set of measurement approaches to define self-efficacy deficits is clearly imperative, as are studies of the role of self-efficacy beliefs among knee osteoarthritis cases with various degrees of disability and sites of pathology. In addition, at present it is not presently clear if cases in the samples studied to date all had a sole diagnosis of knee osteoarthritis, or if they suffered from osteoarthritis of other joints, other forms of arthritis, and/or comorbid conditions, all of possible importance in explaining the observed findings and their implications. In addition, since many studies did not disclose whether they used radiographic assessments of knee osteoarthritis, and other did not use functional tools to assess function, given that self-efficacy beliefs related to self-management practices for knee joint osteoarthritis are likely to be especially impacted among certain disease subgroups, and not others, and to occur in distinctive rather than in all behav- ioral domains, more attention to the clinical and functional presentation of the individual would help to ascertain in what instances selfefficacy enhancing interventions are most indicated. Moreover, identifying why self-efficacy is diminished, and targeting those determinants of suboptimal self-efficacy perceptions, directly, and as early as possible, could be especially helpful for younger adults, and those with unilateral, rather than bilateral joint disease. ${ }^{51}$ To achieve better outcomes and heighten motivation for self-management practices, tailoring management directives in light of gender differences, ${ }^{41}$ as well as health status differences that influence self-efficacy, especially in group-related therapeutic situations, where not all group members will be equally unconfident, and some may be fully confident, is also recommended.

\section{Self-efficacy enhancing interventions and knee osteoarthritis}

Two approaches can enhance self-efficacy, a theory-based approach and a non-theory based approach. Among the theory-based approaches, several reports detailing the outcomes of the Arthritis Self-Management Program (ASMP), have consistently shown participants with arthritis can experience significant early and sustained pain and functional improvements post-intervention. ${ }^{65,66}$ These positive changes also include experiencing less depres- sion, more exercise participation, a heightened ability to relax and self-manage behaviors. ${ }^{63,67}$ Moreover, the program reduces medical services usage and enhances the individual's perception of control, and health status. ${ }^{68}$ Since these improvements have been replicated in many different studies and settings, they appear generalizable across different laboratories. ${ }^{69-73}$ The associated self-efficacy enhancing strategies used by the program developers of skills mastery, modeling, symptom reinterpretation, and persuasion, ${ }^{74}$ have been well validated by Bandura. ${ }^{75}$

Among the atheoretical approaches, a number of recent studies have shown simply participating in an intervention program is better than standard treatment for influencing selfefficacy outcomes for people with osteoarthritis (Table 5), 27,28,52,56,58,76-84 although this finding is not universal as outlined by Hansson et al. ${ }^{85}$ Shen et al. ${ }^{61}$ and Murphy et al. ${ }^{59}$ However, as indicated by findings of Braden et al. ${ }^{70}$ and Lorig and Gonzalez for people with different forms of arthritis, ${ }^{86}$ specific self-efficacy enhancing strategies can be expected to have a greater impact on an individual's sense of confidence than those achieved vicariously, thereby potentially augmenting his or her health status to a greater degree than programs without any tailored and targeted selfefficacy enhancement strategies per se.

In accordance with the results of Braden $e t$ $a l .{ }^{70}$ Lorig and Holman, ${ }^{66}$ and Lorig and Gonzalez, ${ }^{86} 12$ years after implementing the ASMP, this approach conducted by Kovar et al. ${ }^{87}$ in a hospital setting significantly influenced function among patients with disabling knee

Table 4. Mean+standard deviation of overall scores plus item scores for the 5 arthritis selfefficacy subscales of pain and the 6 other symptoms self-efficacy items categorized by gender showing a possible trend whereby males perceive less pain self-efficacy in general, but greater confidence to manage other symptoms than females, despite similarities in age and body mass index.

\begin{tabular}{lccc} 
& $\begin{array}{c}\text { Females } \\
\mathrm{N}=23\end{array}$ & $\begin{array}{c}\text { Males } \\
\mathrm{N}=5\end{array}$ & P valuew \\
Age year & $74.1 \pm 1.4$ & $72 \pm 4.1$ & 0.556 \\
Body mass index & $27.9 \pm .8$ & $29.9 \pm 1.7$ & 0.289 \\
\hline \% Unilateral & 69 & 40 & 0 \\
Overall PSE scores (10-100) & $69.83 \pm 21.40$ & $65.20 \pm 15.27$ & 0.652 \\
PSE1 & $60.87 \pm 32.6$ & $72.0 \pm 21.67$ & 0.476 \\
PSE2 & $67.4 \pm 28.80$ & $74.0 \pm 19.49$ & 0.631 \\
PSE3 & $70.43 \pm 28.04$ & $64.0 \pm 35.07$ & 0.659 \\
PSE4 & $76.74 \pm 27.03$ & $66.00 \pm 24.08$ & 0.421 \\
PSE5 & $75.00 \pm 26.24$ & $6.00 \pm 28.81$ & 0.500 \\
\hline Overall OSE scores (10-100) & $71.80 \pm 21.8$ & $81.20 \pm 23.08$ & 0.394 \\
OSE1 & $74.35 \pm 26.94$ & $82.00 \pm 20.49$ & 0.557 \\
OSE2 & $66.5 \pm 31.99$ & $86.0 \pm 21.90$ & 0.209 \\
OSE3 & $75.22 \pm 29.37$ & $82.0 \pm 24.9$ & 0.636 \\
OSE4 & $73.04 \pm 22.45$ & $88.00 \pm 21.68$ & 0.186 \\
OSE5 & $70.43 \pm 28.2$ & $80.0 \pm 21.16$ & 0.500 \\
OSE6 & $72.56 \pm 27.02$ & $70.00 \pm 42.42$ & 0.394 \\
\hline
\end{tabular}

OSE, other self-efficacy: PSE, pain self-efficacy. 
osteoarthritis, as well as pain. As part of this study of 47 adults with moderate to severe knee joint osteoarthritis, ages 40 to 89 , the author's strove to enhance the participant's self-efficacy and task mastery by exposing them to all four primary experiential sources believed to underpin self-efficacy. They also adopted a step-by-step approach to the program that was organized into four temporal phases for purposes of promoting skill acquisition and maintenance.

Compared to the control condition, the walking self-efficacy intervention yielded clinically meaningful improvements in the participants' walking endurance. The program also yielded significant positive effects in the experimental participants' perception of their physical ability as indicated by the physical activity subscale of the Arthritis Impact Measurement Scale (AIMS). The AIMS scale scores for the participant's ability to manage their arthritis-related symptoms other than pain, were also significantly improved for the intervention subjects. In addition, women with arthritis who received the intervention experienced substantial improvements in their ability to manage other arthritis-related symptoms as assessed by Lorig et al.'s Arthritis Self-efficacy Scale. ${ }^{10}$

As underscored by Rejeski et al.., ${ }^{30}$ the aforementioned approach seems to be a good one because self-efficacy beliefs are likely to have a profound effect on the ability to maintain a viable level of function among older adults with knee pain, especially those challenged by muscular weakness of the lower extremities and chronic disabling osteoarthritis of the knee. To this end, varying additional strategies have been documented in the literature for heightening self-efficacy perceptions including the use of written materials, mutual aid and peer support, telephone interviews and a motivational videotape.
A comprehensive rather than a uni-dimensional approach does seem indicated for improving osteoarthritis self-efficacy attributes as observed by Hansson et al. ${ }^{85}$ who found patient education alone had no effect on the self-efficacy of patients treated in a primary care setting. In particular, exercise, in addition to group education rather than simply including brainstorming and feedback may be helpful, ${ }^{76,85}$ as may a program aimed at promoting independent self-management that incorporates concepts of self-efficacy enhancement theory more definitely. ${ }^{63}$

Thus, Piyakhachornrot et al. ${ }^{79}$ who developed an integrated health education program including exercise based on self-efficacy theory that aimed to enhance self-efficacy expectations among patients with knee osteoarthritis showed positive results in a recent quasi experimental study. In terms of mastery experiences, patients were trained to precisely

Table 5. Selected methods found to impact self-efficacy and knee osteoarthritis symptoms in prospective studies.

$\begin{array}{lll}\text { Authors } & \text { Experimental design } & \text { Key self-efficacy related results } \\ \text { Baker et al. }{ }^{27} & \begin{array}{l}46 \text { cases aged } 55 \text { or older were randomly assigned to home-based } \\ \text { resistance training or control interventions (nutrition education) }\end{array} & \begin{array}{l}\text { SE measured on } 5 \text { scales including lifting, stairclimbing, } \\ \text { walking, jogging, and pushups improved } 34.1 \% \text { in the } \\ \text { experimental group and } 2.0 \% \text { in the control group }\end{array} \\ \text { Focht } \text { et al. }{ }^{28} & \begin{array}{l}\text { The arthritis, diet, and activity promotion program } \\ \text { was applied for } 18 \text { months to } 316 \text { overweight or obese } \\ \text { older adults with symptomatic knee } 0 \mathrm{~A}\end{array} & \text { Mobility-related SE increased significantly }\end{array}$

\begin{tabular}{|c|c|c|}
\hline $\begin{array}{l}\text { Hopman-Rock } \\
\text { and Westhoff } 76\end{array}$ & $\begin{array}{l}\text { Exercise and education was applied to cases with either } \\
\text { hip or knee OA for } 6 \text { weeks }\end{array}$ & Moderate increases in SE were noted and lasted up to 6 months \\
\hline Hughes et al.77 & $\begin{array}{l}\text { Multi-component physical activity program followed } \\
\text { by a home-based program and followed for } 6 \text { months assessed } \\
\text { in part by the efficacy for exercise subscale of } 3 \text { items, } \\
\text { and a score on the 10-point scale was divided by } 3\end{array}$ & $\begin{array}{l}\text { Relative to control subjects, there was an increase in exercise } \\
\text { efficacy at } 2 \text { months, and at } 6 \text { months, this was significantly higher } \\
\text { compared to control group where this value declined }\end{array}$ \\
\hline Kim et al.78 & $\begin{array}{l}\text { An aquarobic exercise program and patient education program } \\
\text { lasting } 60 \text { minutes for } 36 \text { sessions was held } 3 \text { times per week } \\
\text { for } 22 \text { cases of knee } \mathrm{OA} \text { and } 29 \text { controls plus } 22 \\
\text { with other forms of } \mathrm{OA}\end{array}$ & $\begin{array}{l}\text { SE as assessed by an adapted ASES tool consisting of } 14 \text { items on } \\
\text { a } 10 \text { point Likert scale increased from } 1124.87 \text { to } 1251.46 \text { after the } \\
\text { intervention; while the control group dropped from } 1166.00 \text { at } \\
\text { baseline to } 1018.65 \text { on post test }\end{array}$ \\
\hline
\end{tabular}

$\begin{array}{lll}\text { King et al. }{ }^{56} & 14 \text { young adults underwent high intensity isokinetic training } & \text { High intensity exercise training produced increases in the ASES } \\ & 3 \text { times per week for } 12 \text { weeks } & \text { function domain, from } 8.37 \pm 0.86 \text { to } 8.80 \pm 0.65\end{array}$

Lamb et al.58 Chronic disease management program for 121 cases $\quad$ Pain and function SE increased among other factors
with severe $\mathrm{OA}$

\begin{tabular}{|c|c|c|}
\hline Piyakhachornrot et al..$^{79}$ & $\begin{array}{l}73 \text { middle aged adults with knee OA were assigned to one } \\
\text { of two intervention groups that received integrated health } \\
\text { education and exercises, SE expectations were promoted } \\
\text { through a theory based } 4 \text { step approach }\end{array}$ & $\begin{array}{l}\text { Mean SE expectation scores assessed on a } 15 \text {-item questionnaire } \\
\text { with total scores ranging from } 0-30 \text { increased from baseline to } 8 \\
\text { weeks and } 12 \text { weeks }\end{array}$ \\
\hline Rawiworrakul et al. ${ }^{60}$ & $\begin{array}{l}\text { Women were exposed to a community-based exercise } \\
\text { program to support self-efficacy strategies twice weekly } \\
\text { for } 12 \text { weeks among an experimental group, }\end{array}$ & $\begin{array}{l}\text { Increased SE for exercise, severity symptoms and physical } \\
\text { performance was detected at week } 4 \text { for the experimental group, } \\
\text { but not at week } 12\end{array}$ \\
\hline
\end{tabular}

\begin{tabular}{lll} 
Rejeski et al. ${ }^{22}$ & $\begin{array}{l}\text { Aerobic or resistance training or health education programs } \\
\text { were applied to } 357 \text { older adults with knee OA }\end{array}$ & Both exercise treatments increased SE for stair climbing \\
\hline Wang et al. ${ }^{80}$ & $\begin{array}{l}\text { Prospective, single-blinded, randomized controlled trial } \\
\text { of Tai Chi for } 40 \text { individuals with symptomatic tibiofemoral }\end{array}$ & $\begin{array}{l}\text { Program resulted in improved SE on a 1-5 point scale and this was } \\
\text { maintained at } 24 \text { and } 48 \text { weeks }\end{array}$
\end{tabular}

Yip et al. .182 $^{1,2}$ Randomized theory-based self-management trial with exercise component with 120 participants followed for 16 weeks, then 1 year
At 16 weeks arthritis SE improved in most domains; and at one year pain SE increased; as did other symptoms SE for experimental group, along with reduced pain and medical visits

ASES, arthritis self-efficacy scale; OA, osteoarthritis; SE, self-efficacy. 
carry out their exercise regimens. They received demonstrations on how to do this and watched a patient with a similar condition carry this out. They were specifically encouraged to engage in exercise or perform activities related to reducing knee symptoms they had learned. To reduce emotional arousal they discussed and shared strategies for reducing barriers to exercise and participants were trained until they felt confident to exercise.

Other factors may influence the degree of success of any program designed to enhance a knee osteoarthritis patient's confidence to self-manage their disease. These include the extent of any prevailing pain and mood disorder, concurrent disease activity and/or severity, health or age status, ${ }^{88}$ stages-of-change profiles among patients and the interventionist's or intervention approach. ${ }^{57,89,90}$ In addition, optimal health outcomes might be specifically enhanced by the appropriate education of spouses, significant family members and caregivers, ${ }^{83,91}$ the implementation of individually tailored goal-directed exercise programs, ${ }^{62,92,93}$ and mutuality, rather than paternalism in goal setting. ${ }^{92}$ Social persuasion, physiological feedback, and problem solving may be equally highly beneficial, ${ }^{62,93}$ as may breaking down goals into achievable steps, followed by graduated opportunities to achieve task mastery. ${ }^{62,92}$ ${ }_{95}$ Discussions concerning previous adverse experiences with the behavior in question, along with an appropriate action plan plus simulations of the desired behavior are potentially helpful as well. $.6,97$

In particular, interventions guided by selfefficacy theory may produce more robust effects than those that are not even though few comparative studies exist to support this view. Alternately, since each probably has its own place in the rehabilitation process, the clinician can carefully examine where confidence is lacking in the context of the clinical presentation of the disease, so they can effectively tailor their recommendations accordingly.

\section{Discussion and Conclusions}

Knee osteoarthritis, a prevalent costly health condition is commonly associated with pain and functional disability. To retard the progression of and/or reduce the magnitude of the disability arising from this incurable condition, where joint changes alone do not predict symptoms, ${ }^{32,40}$ and where overlapping physiological, physical, and psychosocial risk factors can prevail, 54 the affected individual may need to carry out one or more novel intervention strategies on a consistent basis despite the presence of unrelenting pain and discomfort. These strategies may include but are not limited to:

\section{- Exercise.}

Weight reduction.

Joint protection and energy conservation strategies.

- Use of assistive devices.

- A variety of medication regimens.

- Home and workplace modifications.

- The application of electrotherapeutic devices.

Fortunately, an increasing body of evidence supports a key role for investigating and intervening upon intra-individual factors that may inhibit motivation for participating in or carrying out one or more of the above mentioned self-management or adaptive strategies and others. ${ }^{34,41}$ In particular, efforts to boost selfefficacy for achieving a desired goal, including exercise, function and pain self-efficacy, ${ }^{31,33}$ may causally influence the ability of the patient to both adjust to and successfully manage their knee osteoarthritis and its attendant pain and disability. ${ }^{30,34,65}$ Additional research reveals that efforts to raise a client's self-efficacy may also predict depression and enhance the facility of adults with osteoarthritis to inhibit or discontinue unfavorable behaviors plus the adoption and maintenance of generally favorable health behaviors, especially physical activity. 14,15,30,98,99

Thus, despite the inherent limitations in cross-sectional research, the possibility that those who have been studied already have acceptable self-efficacy, ${ }^{58}$ and the fact that some aspects of self-efficacy for managing knee osteoarthritis may not improve over time despite attempts to enhance this, ${ }^{77}$ taken as a whole, the available evidence strongly suggests that regardless of numbers of affected joint sites, and assessment approach, the extent of one's self-efficacy beliefs can tentatively predict who may or may not benefit from a specific mode of treatment and thus steps to address confidence issues should not be overlooked in the context of managing knee osteoarthritis as discussed by Bennett et al. ${ }^{33}$ Since self-reported disability in individuals with knee osteoarthritis is strongly related to pain, and anxiety, among other treatable factors, ${ }^{32}$ and these can both be influenced by the magnitude of the individuals self-efficacy beliefs, routinely assessing the magnitude and specificity of these beliefs and intervening accordingly to maximize any significant deficit over time may help clinicians to offset the totality of the disability experienced by these individuals as a result of reduced confidence levels, especially if tailored in light of recent symptoms and demographic characteristics. ${ }^{77,100}$

In this regard, as outlined by Fitzgerald and depicted in Figure 2,48 carefully construed timely efforts to examine and raise suboptimal self-efficacy beliefs, especially where these are low, will predictably yield important and beneficial outcomes among cases with symptomatic knee osteoarthritis, including higher life satisfaction, ${ }^{42}$ reduced pain and stiffness, ${ }^{46,79}$ and higher function. ${ }^{34,46,79}$ Additionally, a careful assessment of self-efficacy followed by multicomponent interventions to specifically enhance this is predicted to favorably influ-

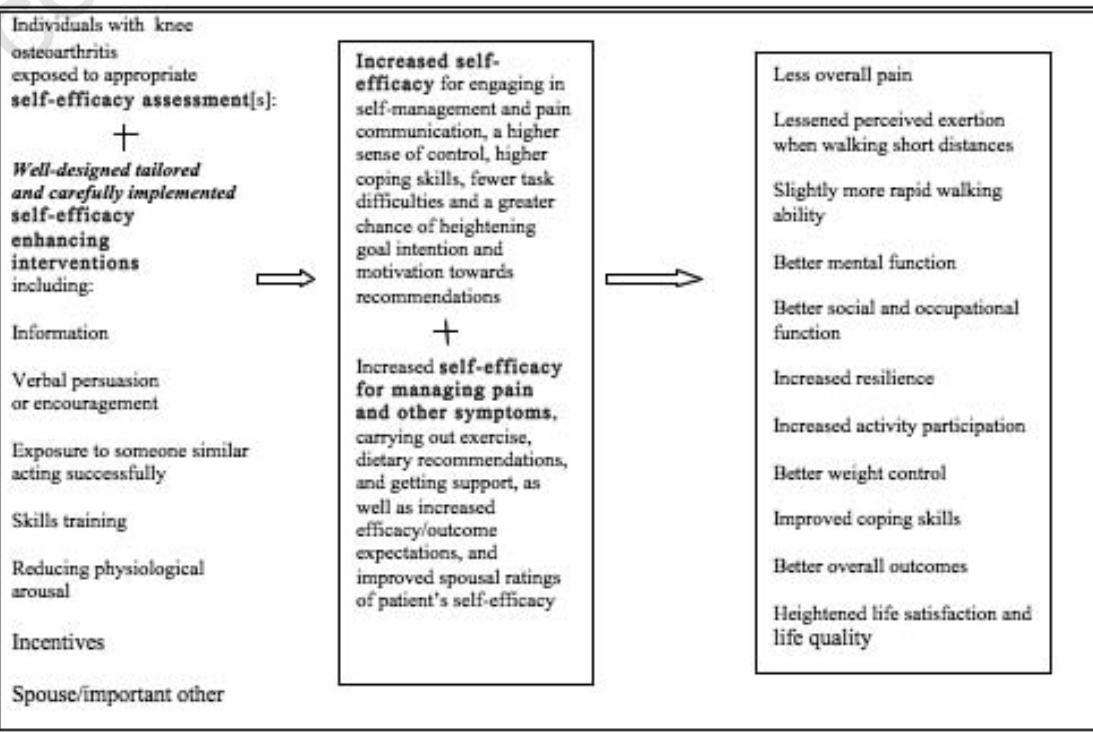

Figure 2. Logic model of proposed outcomes of self-efficacy theory based interventions and others as applied to the management of adults with knee osteoarthritis. Sources: Bandura $^{2}$; Dekker et al.52; Danush et al.90, Keefe et al..$^{77}$; Maly et al. ${ }^{37}$; Mann and Gooberman-Hill ${ }^{102}$; Pattayakorn et al. ${ }^{92}$; Piyakhachornro et al. ${ }^{74}$; Porter et al. ${ }^{96}$; Rawiworrakul et al. ${ }^{101}$; Rejeski et al. ${ }^{29}$; Wang et al. ${ }^{94}$ 
ence knee osteoarthritis outcomes as outlined in Figure 2. Moreover, research suggests those younger than 60 years of age, and those with comorbid health conditions, and clinical depression might be especially assisted to overcome their challenges using this approach.

Although no one mode of intervention has been deemed superior to another, interventions that follow Bandura's systematic strategy appear to generate consistently positive outcomes, ${ }^{2,34}$ although other approaches listed in Table 5 including interventions that focus on pain communication processes, ${ }^{101}$ as well as decreasing the factors producing low self-efficacy beliefs, such as knee muscle weakness may be helpful. ${ }^{34}$ Including the patient as well as family members and important others in the rehabilitation process, reducing maladaptive pain coping strategies, ${ }^{35}$ and intervening early to minimize excessive catastrophizing is also indicated. ${ }^{37,57}$

However, to enable adults with knee osteoarthritis to experience a higher life quality than those presently attainable, despite their pathology, research efforts to examine these premises using more domain specific tools and long-term measurement approaches are highly recommended. As well, since the optimal mode of intervention for enhancing self-efficacy in the context of knee osteoarthritis subpopulations is not known, more comparative research to examine the efficacy and/or nature of failures of those approaches reported in Table 5 as regards self-efficacy outcomes is recommended as well. Meantime, health professionals are strongly encouraged to routinely assess and examine the global self-efficacy beliefs of their knee osteoarthritis clients as well as employ or develop behavior-specific self-efficacy scales such as the coping efficacy scale to derive specific guidelines for better targeted treatments (e.g. Wang et al.). ${ }^{102}$ Remaining cognizant of the fact self-efficacy is a complex construct with potential gender and racial differences in self-efficacy beliefs, and is likely to be differentially influenced by age, will be helpful as well. ${ }^{34,55}$ Salient variations in disease presentation and related perceptions should be recognized and interventions should be targeted and tailored accordingly, as discussed by Murphy et al. ${ }^{100}$ Finally, the consistent use of functional outcome measures ${ }^{46}$ radiographic assessments, ${ }^{34}$ and measurements of opioid activation, ${ }^{103}$ as well as researching which patients with knee osteoarthritis are potentially predisposed to low self-efficacy for a particular behavior, and what constitutes the most beneficial mode of providing information to raise confidence early on in the management process, ${ }^{104}$ which has not been studied, might be especially valuable.

\section{References}

1. March L, Amatya B, Osborne RH, et al. Developing a minimum standard of care for treating people with osteoarthritis of the hip and knee. Best Pract Res Clin Rheumatol 2010;24;121-45.

2. Bandura A. Social learning theory. Englewood Cliffs, NJ: Prentice Hall; 1977.

3. 0'Leary A. Self-efficacy and health. Behav Res Ther 1985;23:437-61.

4. Dolce JJ. Self-efficacy and disability beliefs in behavioral treatment of pain. Behav Res Ther 1987;25:289-99.

5. Van Dijk GM, Veenhof C, Lankhorst GJ, et al. Limitations in activities in patients with osteoarthritis of the hip or knee: the relationship with body functions, comorbidity and cognitive functioning. Disabil Rehabil 2009;31:1685-91.

6. Bijlsma JW, Knahr K. Strategies for the prevention and management of osteoarthritis of the hip and knee. Best Pract Res Clin Rheumatol 2007;21:59-76.

7. Prior KN, Bond MJ. The roles of self-efficacy and abnormal illness behavior in osteoarthritis self-management. Psychol Hlth Med 2004;9:177-92.

8. Petrella RJ, Decraria J, Petrella MJ. Long term efficacy and safety of a combined low and high molecular weight hyaluronic acid in the treatment of osteoarthritis of the knee. Rheumatol Rep 2010;3:e416-21.

9. Bierma-Zeinstra SM, Verhagen AP. Osteoarthritis subpopulations and implications for clinical trial design. Arthritis Res Ther 2011;13:213.

10. Lorig K, Chastain RL, Ung E, et al. Development and evaluation of a scale to measure perceived self-efficacy in people with arthritis. Arthritis Rheum 1989;32:3744.

11. Taal E, Rasker JJ, Seydel ER, et al. 0. Health status, adherence with health recommendations, self-efficacy and social support in patients with rheumatoid arthritis. Patient Educ Couns 1993;20:6376.

12. Dirik G, Karanci AN. Psychological distress in rheumatoid arthritis patients: an evaluation within the conservation of resources theory. Psychol Hlth 2009;6:1-16.

13. Van Hoogmoed D, Fransen J, Bleijenberg G, et al. Physical and psychosocial correlates of severe fatigue in rheumatoid arthritis. Rheumatology (Oxford) 2010; 49:1294-302.

14. Lefebvre JC, Keefe FJ, Affleck G, et al. The relationship of arthritis self-efficacy to daily pain, daily mood, and daily pain coping in rheumatoid arthritis patients. Pain 1999;80:425-35.

15. Gyurcsik NC, Brawley LR, Sprink KS, et al.
Physical activity in women with arthritis: examining perceived barriers and self-regulatory efficacy to cope. Arthritis Rheum 2009;61:1087-94.

16. Blamey R, Jolly K, Greenfield S, et al. Patterns of analgesic use, pain and selfefficacy: a cross-sectional study of patients attending a hospital rheumatology clinic. BMC Musculoskelet Disord 2009;10:137.

17. Buescher KL, Johnston JA, Parker JC, et al. Relationship of self-efficacy to pain behavior. J Rheumatol 1991;18:968-72.

18. Brekke M, Hjortdahl P, Kvien TK. Self-efficacy and health status in rheumatoid arthritis: a two-year longitudinal observational study. Rheumatol 2001;40:387-92.

19. Buckelew SP, Huyser B, Hewett JE, et al. Self-efficacy predicting outcome among fibromyalgia subjects. Arthr Care Res 1996;9:97-104.

20. Reinseth L, Uhlig T, Kjeken I, et al. Performance in leisure-time physical activities and self-efficacy in females with rheumatoid arthritis. Scand J Occup Ther 2011;18:210-8.

21. Packham JC, Hall MA, Pimm TJ. Long-term follow-up of 246 adults with juvenile idiopathic arthritis: predictive factors for mood and pain. Rheumatol 2002;41:14449.

22. Beckham JC, Burker E J, Rice JR, et al. Patient predictors of caregiver burden, optimism and pessimism in rheumatoid arthritis. Behav Med 1995;20:171-8.

23. Riesma RP, Rasker JJ, Taal E, et al. Fatigue in rheumatoid arthritis: the role of selfefficacy and problematic social support. $\mathrm{Br}$ J Rheumatol 1998;37:1042-6.

24. Smarr KL, Parker JC, Wright GE, et al. The importance of enhancing self-efficacy in rheumatoid arthritis. Arthritis Care Res 1997;10:18-26.

25. Brus H, van de Laar M, Taal E, et al. Determinants of compliance with medication in patients with rheumatoid arthritis: the importance of self-efficacy expectations. Patient Educ Couns 1997;36:57-64.

26. Cross MJ, March LM, Lapsley HM, et al. Patient self-efficacy and health locus of control: relationships with health status and arthritis-related expenditure. Rheumatology (Oxford) 2006;45:92-6.

27. Baker KR, Nelson ME, Felson DT, et al. The efficacy of home based progressive strength training in older adults with knee osteoarthritis: a randomized controlled trial. J Rheumatol 2001;28:1655-65.

28. Focht BC, Rejeski WJ, Ambrosius WT, et al. Exercise, self-efficacy, and mobility performance in overweight and obese older adults with knee osteoarthritis. Arthritis Rheum 2005;53:659-65.

29. Maly MR, Costigan PA, Olney SJ. Determinants of self-report outcome 
measures in people with knee osteoarthritis. Arch of Phys Med Rehabil 2006;87:96104.

30. Rejeski WJ, Craven T, Ettinger WH Jr, et al. Self-efficacy and pain in disability with osteoarthritis of the knee. J Gerontol B Psychol Sci Soc Sci 1996;51:P24-9.

31. Sharma L, Cahue S, Song J, et al. Physical functioning over three years in knee osteoarthritis: role of psychosocial, local mechanical, and neuromuscular factors. Arthritis Rheum 2003;48:3359-70.

32. Creamer P, Lethbridge-Cejku M, Hochberg MC. Factors associated with functional impairment in symptomatic knee osteoarthritis. Rheumatology (Oxford) 2000;39: 490-6.

33. Bennett AN, Crossley KM, Brukner PD, et al. Predictors of symptomatic response to glucosamine in knee osteoarthritis: an exploratory study. Br J Sports Med 2007;41: 415-9.

34. Harrison AL. The influence of pathology, pain, balance, and self-efficacy on functioning women with osteoarthritis of the knee. Phys Ther 2004;84:822-31.

35. Keefe FJ, Lefebvre JC, Maixner W, et al. Self-efficacy for arthritis pain: relationship to perception of thermal laboratory pain stimuli. Arthritis Care Res 1997; 10:177-84.

36. Khan CM, Iida M, Stephens MA, EM, et al. Spousal support following knee surgery: roles of self-efficacy and perceived emotional responsiveness. Rehabil Psychol 2009;54:28-32.

37. McKnight PE, Afram A, Kashdan TB, et al. Coping self-efficacy as a mediator between catastrophizing and physical functioning: treatment target selection in an osteoarthritis sample. J Behav Med 2010; $33: 239-49$.

38. Morone NE, Karp JF, Lynch CS, et al. Impact of chronic musculoskeletal pathology on older adults: a study of differences between knee $\mathrm{OA}$ and low back pain. Pain Med 2009;10:693-701.

39. Pells JJ, Shelby RA, Keefe FJ, et al. Arthritis self-efficacy and self-efficacy for resisting eating: relationships to pain, disability, and eating behavior in overweight and obese individuals with osteoarthritic knee pain. Pain 2008;136:340-7.

40. Wright LJ, Zautram AJ, Going S. Adaptation to early knee osteoarthritis: the role of risk, resilience, and disease severity on pain and physical functioning. Ann Behav Med 2008;36:70-80.

41. Gaines JM, Talbot LA, Metter EJ. The relationship of arthritis self-efficacy to functional performance in older men and women with osteoarthritis of the knee. Geriatr Nurs 2002;23:167-70.

42. Pattayakorn P, Hanucharurnkul S,
Goeppinger J, et al. Factors influencing life satisfaction among older Thai women with knee osteoarthritis. Pacific Rim Int J Nurs Res 2010;14:3-16.

43. Wilcox S, Brenes GA, Levine D, et al. Factors related to sleep disturbance in older adults experiencing knee pain or knee pain with radiographic evidence of knee osteoarthritis. J Am Geriatr Soc 2000;48:1241-51.

44. Topp R, Woolley S, Khuder S, et al. Predictors of four functional tasks in patients with osteoarthritis of the knee. Orthop Nurs 2000;19:49-58.

45. Maly MR, Costigan PA, Olney SJ. Determinants of self efficacy for physical tasks in people with knee osteoarthritis. Arthritis Rheum 2006;15:94-101.

46. Maly MR, Costigan PA, Olney SJ. Self-efficacy mediates walking performance in older adults with knee osteoarthritis. J Gerontol A Biol Sci Med Sci 2007;62:11426.

47. Wylde V, Dixon S, Blom AW. The role of preoperative self-efficacy in predicting outcome after total knee replacement. Musculoskeletal Care. 2012;10:110-8. doi: 10.1002/msc.1008. Epub 2012 Feb 24.

48. Fitzgerald GK. Therapeutic exercise for knee osteoarthritis: considering factors that may influence outcome. Eura Medicophys 2005;41:163-71.

49. Dunn J, Chimielski TL. Changes in psychological factors and function in a patient with bilateral knee osteoarthritis: a case study. Orthop Phys Ther Pract 2008;20:18792.

50. Bennell KL, Hinman RS. A review of the clinical evidence for exercise in osteoarthritis of the hip and knee. J Sci Med Sport 2011;14:4-9.

51. Marks R. Physical and psychological correlates of disability among a cohort of individuals with knee osteoarthritis. Can J Aging 2007;26:367-77.

52. Rejeski WJ, Ettinger WH, Martin K, Morgan T. Treating disability in knee osteoarthritis with exercise therapy: a central role for self-efficacy and pain. Arthritis Care Res 1998;11:94-101.

53. De Boer IG, Peeters AJ, Ronday HK, et al. Assistive devices: usage in patients rheumatoid arthritis. Clin Rheumatol 2009;28;119-928.

54. Dekker J, Van Dijk GM, Veenhof C. Risk factors for functional decline in osteoarthritis of the hip or knee. Curr Opinion Rheumatol 2009;21:520-4.

55. Allen KD, Oddone EZ, Coffman CJ, et al. Racial differences in osteoarthritis pain and function: potential explanatory factors. Osteoarthritis Cartilage 2010;18:1607.

S, 56. King LK, Birmingham TB, Kean CO, et al.
Resistance training for medial compartment knee osteoarthritis and malalignment. Med Sci Sports Exerc 2008;40:137684.

57. Keefe FJ, Lefebvre JC, Kerns RD, et al. Understanding the adoption of arthritis self-management: stages of change profiles among arthritis patients. Pain 2000;87:303-33.

58. Lamb SE, Toye F, Barker KL. Chronic disease management programme in people with severe knee osteoarthritis: efficacy and moderators of response. Clin Rehabil 2008;22:169-78.

59. Murphy SL, Strasburg DM, Lyden AK, et al. Effects of activity strategy training on pain and physical activity in older adults with knee or hip osteoarthritis: a pilot study. Arthritis Rheum 2008;59:1480-7.

60. Rawiworrakul T, Sirapo-ngam Y, Davis A, et al. A community-based exercise program promotes self-efficacy for exercise among Thai women with osteoarthritis of the knee. Thai J Nurs Res 2007;11:132-50.

61. Shen CL, James CR, Chyu MC, et al. Effects of Tai Chi on gait kinematics, physical function, and pain in elderly with knee osteoarthritis - a pilot study. Am J Chin Med 2008;36:219-32.

62. Schlenk EA, Lias JL, Sereika SM, et al. Improving physical activity and function in overweight and obese older adults with osteoarthritis of the knee: a feasibility study. Rehabil Nurs 2011;36:32-42.

63. Wu SF, Kao MJ, Wu MP, et al. Effects of an osteoarthritis self-management programme. J Adv Nurs 2011;67:1491-501.

64. Engel C, Hamilton NA, Potter P, et al. Impact of two types of expectancy on recovery from total knee replacement surgery (TKR) in adults with osteoarthritis. Behav Med 2004;30:113-23.

65. Holman H, Mazonson P, Lorig K. Health education for self-management has significant early and sustained benefits in chronic arthritis. Trans Assoc Am Phys 1989;102;204-8.

66. Lorig K, Holman H. Arthritis self-management studies: a 12-year review. Health Educ Q 1993;20:17-28.

67. Lorig K, Lubeck D, Kraines RG, et al. Outcomes of self-help education for patients with arthritis. Arthritis Rheum 1985;28:680-5.

68. Barlow JH, Turner AP, Wright CC. Longterm outcomes of an arthritis self-management programme. Brit J Rheumatol 1998;37:1315-9.

69. Barlow JH, Barefoot J. Group education for people with arthritis. Patient Educ Couns 1996;27:257-67.

70. Braden CJ, McGlone K, Pennington F. Specific psychosocial and behavioral outcomes from the systemic lupus erythe- 
matosus self-help course. Health Educ Q 1993;20:29-41.

71. Devos-Comby L, Cronan T, Roesch SC. Do exercise and self-management interventions benefit patients with osteoarthritis of the knee? A metaanalytic review. J Rheumatol 2006;33:744-56.

72. Barlow JH, Williams B, Wright CC. Instilling the strength to fight the pain and get on with life: learning to become an arthritis self-manager through an adult education programme. Health Educ Res 1999;14:533-44.

73. Barlow J, Turner A, Swaby L, et al. An 8-yr follow-up of arthritis self-management programme participants. Rheumatology (Oxford) 2009;48:128-33.

74. Lorig KR, Ritter PL, Laurent DD, et al. The internet-based arthritis self-management program: a one-year randomized trial for patients with arthritis or fibromyalgia. Arthritis Rheum 2008;59:1009-17.

75. Bandura A. Social foundations of thought and action: a social cognitive theory. Englewood Cliffs, NJ: Prentice Hall; 1986.

76. Hopman-Rock M, Westhoff M. The effects of a health education and exercise program for older adults with osteoarthritis of the hip or knee. J Rheumatol 2000;27: 1947-54.

77. Hughes SL, Seymour RB, Campbell RT, et al. Fit and Strong!: bolstering maintenance of physical activity among older adults with lower-extremity osteoarthritis. Am J Health Behav 2010;34:750-63.

78. Kim I-S, Chung S-H, Park Y-J, et al. The effectiveness of an aquarobic exercise program for patients with osteoarthritis. Appl Nurs Res 2012;25:181-9.

79. Piyakhachornrot N, Aree-Ue S, Putwatana $\mathrm{P}$, et al. Impact of an integrated health education and exercise program in middleaged Thai adults with osteoarthritis of the knee. Orthop Nurs 20111;30:134-42.

80. Wang C, Schmid CH, Hibberd PL, et al. Tai Chi is effective in treating knee osteoarthritis: a randomized controlled trial. Arthritis Rheum 2009;61:1545-53.

81. Yip YB, Sit JW, Fung KK, et al. Effects of a self-management arthritis programme with an added exercise component for osteoarthritic knee: randomized controlled trial. J Adv Nurs 2007;59:20-8.

82. Yip Y, Sit J, Wong D, et al. A 1-year follow- up of an experimental study of a self-management arthritis programme with an added exercise component of clients with osteoarthritis of the knee. Psychol Health Med 2008;13:402-14.

83. Keefe FJ, Caldwell DS, Baucom D, et al. Spouse assisted coping skills training in the management of osteoarthritic knee pain. Arthritis Care Res 1996;9:279-91.

84. Edworthy SM, Devins GM. Improving medication adherence through patient education distinguishing between appropriate and inappropriate utilization. Patient education study group. J Rheumatol 1999;26: 1647-9.

85. Hansson EE, Jönsson-Lundgren M, Ronnheden AM, et al. Effect of an education programme for patients with osteoarthritis in primary care - a randomized controlled trial. BMC Musculoskelet Disord 2010;11:244.

86. Lorig K, Gonzalez V. The integration with practice: a 12-year case study. Health Educ Q 1992;19:355-68.

87. Kovar PA, Allegrante JP, MacKenzie CR, et al. Supervised fitness walking in patients with osteoarthritis of the knee: a randomized, controlled trial. Ann Int Med 1992; 116:529-34.

88. Bennell KL, Messier SP. Osteoarthritis: strength training, self-management or both for early knee OA. Nature Rev Rheumatol 2010;6:313-4.

89. Solomon DH, Warsi A, Brown-Stevenson T, et al. Does self-management education benefit all populations with arthritis? A randomized controlled trial in a primary care physician network. J Rheumatol 2002; 29:362-8.

90. Allegrante JP, Marks R. Self-efficacy in management of osteoarthritis. Rheum Dis Clin North Am 2003;29:747-68.

91. Keefe FJ, Susmita KZ, Robinson E, et al. Pain coping strategies that predict patients' and spouses' ratings of patients' self-efficacy. Pain 1997;73:191-9.

92. Stenstrom $\mathrm{CH}$. Home exercise in rheumatoid arthritis functional class II: goal setting versus pain attention. J Rheumatol 1994;21:627-34.

93. Jensen GM, Lorish CD. Promoting patient cooperation with exercise programs. Linking research, theory and practice. Arthritis Care Res 1994;7:181-9.
94. Marks R. Efficacy theory and its utility in arthritis rehabilitation: review and recommendations. Disabil Rehabil 2001;23:27180.

95. Marks R, Allegrante JP, Lorig K. A review and synthesis of research evidence for self-efficacy-enhancing interventions for reducing chronic disability: implications for health education practice (part II). Health Promot Pract 2005;6:148-56.

96. Elder JP, Ayala GX, Harris S. Theories and intervention approaches to health-behavior changes in primary care. Am J Prev Med 1999;17:275-84.

97. Gage M, Polatajko H. Enhancing occupational performance of perceive self-efficacy. Am J Occup Ther 1994;48:452-61.

98. Jensen MP, Turner JA, Romano JM. Self efficacy and outcome expectations: relationship to chronic pain coping strategies and adjustment. Pain 1991;44:263-9.

99. Damush T, Perkins S, Mikesky A, et al. Motivational factors influencing older adults diagnosed with knee osteoarthritis to join and maintain an exercise program. J Aging Phys Act 2005;13:45-60.

100.Murphy SL, Lyden AK, Smith DM, et al. Effects of a tailored activity pacing intervention on pain and fatigue for adults with osteoarthritis. Am J Occup Ther 2010;64: 869-76.

101.Porter LS, Keefe FJ, Wellington C, et al. Pain communication in the context of osteoarthritis: patient and partner selfefficacy for pain communication and holding back from discussion of pain and arthritis-related concerns. Clin J Pain 2008;24:662-8.

102.Wang P, Badle EM, Gignac M. Activity limitation, coping efficacy and self-perceived physical independence in people with disability. Disabil Rehabil 2004;26;785-93.

103.Bandura A, Cioffi D, Taylor CB, et al. Perceived self-efficacy in coping with cognitive stressors and opioid activation. J Pers Soc Psychol 1988;55:479-88.

104.Mann C, Gooberman-Hill R. Health care provision for osteoarthritis: concordance between what patients would like and what health professionals think they should have. Arthritis Care Res 2011;63: 963-72. 